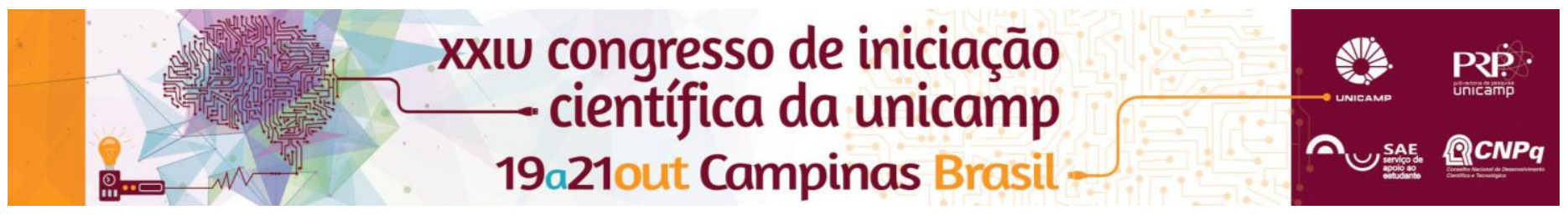

\title{
INTERFERÊNCIA DA MEDULA, DE NÓS E DO SISTEMA DE INTERPOLAÇÃO EM IMAGENS DE TOMOGRAFIA ULTRASÔNICA.
}

\author{
Guilherme A. Martins*, Raquel Gonçalves, Stella S. A. Palma.
}

\begin{abstract}
Resumo
A identificação da condição interna de árvores é um problema atual importante, tanto para o setor urbano quanto florestal. Equipamentos de tomografia acústica permitem obter imagens da condição interna de árvores. No entanto os existentes no mercado são importados e muito onerosos, fazendo com que a tecnologia seja muito limitada em nosso país. Esse projeto de iniciação científica está incorporado a esforço do grupo de pesquisa em Ensaios Não Destrutivos da FEAGRI/Unicamp, visando o desenvolvimento de tomografia ultrassônica com tecnologia nacional. O objetivo deste projeto de IC foi caracterizar o nível de interferência da presença de medula e de nós nas imagens de tomografia ultrassônica geradas. Os resultados preliminares indicam que zonas de madeira de reação tendem a apresentar velocidades inferiores (cerca de $30 \%$ da máxima), enquanto regiões com nó velocidades máximas. No entanto não é esperado que tais variações interfiram na identificação de deteriorações, já que as velocidades em discos íntegros, com presença apenas de nós ou medula deslocada, em geral apresentaram velocidades sempre superiores a $70 \%$ da velocidade máxima obtida no proprio disco.
\end{abstract}

Palavras-chave: ensaio não destrutivo, inspeção de árvores, tomografia ultrassônica.

\section{Introdução}

Em centros urbanos a queda de árvore é uma grande preocupação do poder público, pois provocam graves acidentes e prejuízos econômicos. A tomografia acústica aplicada em árvores, com o objetivo de analisar a presença de anomalias ou deteriorações, é baseada na geração de imagens produzidas por meio de diferenciação de cores, que representam faixas de velocidades obtidas no material sob inspeção. Diversos são os tipos de defeitos (ocos, fendas ou zonas atacadas por fungos e cupins) ou singularidades (nós, bolsas de resina, medula deslocada) que podem ocorrer em árvores. Todos estes defeitos e singularidades afetam, em menor ou maior grau, a estrutura anatômica do material e, como consequência, a velocidade de propagação das ondas. O objetivo deste projeto de IC foi caracterizar o nível de interferência da presença de medula e de nós nas imagens de tomografia ultrassônica geradas utilizando equipamento e software nacionais. Essa avaliação é importante, pois árvores em geral apresentam essas singularidades e é necessário saber se tais singularidades tem 0 potencial de afetar a identificação de defeitos.

\section{Resultados e Discussão}

A avaliação está sendo realizada por meio da geração das imagens utilizando o software ImageWood 2.0, as quais são comparadas com as fotos de cada disco. Para a geração das imagens foi estabelecido um padrão de cores para representar 6 faixas de velocidades: $V_{\text {MIN }}$ até $20 \%$ da $\mathrm{V}_{\text {MAX: }}$ : vermelho; de $20 \%$ a $30 \%$ da $\mathrm{V}_{\text {MAX }}$ : rosa; de $30 \%$ a $50 \%$ da $\mathrm{V}_{\text {MAX: }}$ : amarelo; de $50 \%$ a $70 \%$ da $\mathrm{V}_{\text {MAX: }}$ verde; de $70 \%$ a $80 \%$ da $\mathrm{V}_{\mathrm{MAX}}$ : laranja e de $80 \%$ até a $\mathrm{V}_{\mathrm{MAX}}$ : marrom.

A análise realizada até agora mostrou que, em geral, os discos com presença de nós e de medula deslocada apresentam apenas as cores verde, laranja e marrom, indicando velocidades variando no disco de $70 \%$ a $100 \%$ da velocidade máxima (Exemplo na Figura 1). Essa variação é considerada normal para um material heterogêneo e ortotrópico como é o caso da madeira.

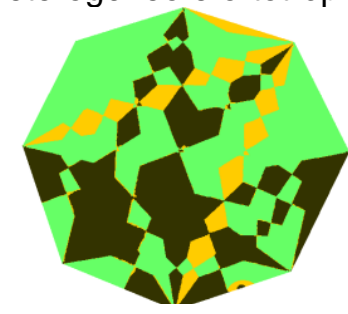

a

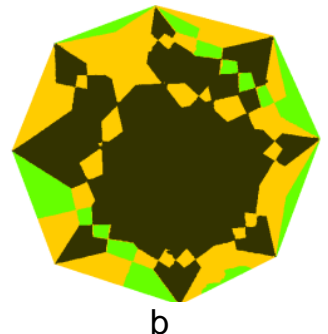

b
Figura 1. Ex de imagem gerada em disco com presença de medula deslocada - disco 1(a) e nó - disco 16 (b)

As comparações das imagens geradas pelo software com as fotos dos discos (Figura 2) indicam, até o momento, que em zonas com medula as velocidades são cerca de $30 \%$ inferiores às máximas (verde) enquanto em regiões com nó as velocidades são de $80 \%$ a $100 \%$ da máxima (marrom).

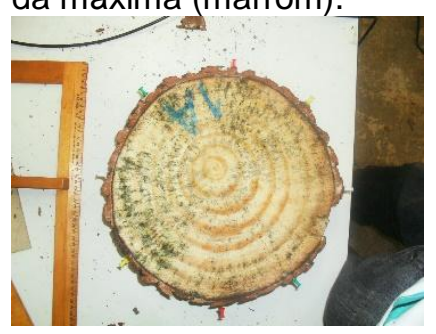

a

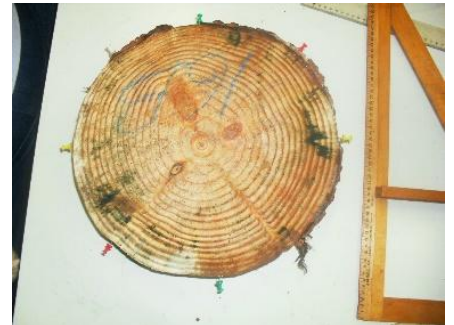

b
Figura 2. Ex de fotos de disco com presença de medula deslocada - disco 1(a) e nó - disco 16 (b)

\section{Conclusões}

A pesquisa ainda está em andamento, logo não temos resultados conclusivos ainda. No entanto, esperamos explicar se a presença de medula e/ou nós interferem nas imagens geradas pelo software desenvolvido pelo grupo.

\section{Agradecimentos}

FAPESP (Proc. 2011/08286-5; 2015/05692-3) pelo apoio a pesquisa e CNPq e CAPES pelas bolsas de estudo. 